\title{
Research on Social Network and Farmers' Safety Production Behavior
}

\author{
Jialin Zhu \\ Western Rural Development Research Center \\ Northwest A\&F University \\ Shaanxi Yangling China \\ E-mail:zhujialin_kk@163.com
}

\author{
Tianjun Liu* \\ Western Rural Development Research Center \\ Northwest A\&F University \\ Shaanxi Yangling China \\ E-mail:Itj168168@nwsuaf.edu.cn
}

\begin{abstract}
This article adopts the micro survey data of 186 farmer households in the main apple production area of Liquan County, Xianyang City, Shaanxi Province. Using the typical correlation analysis, from the perspective of social network function, the social network is studied according to three dimensions of network learning, network trust, and network interaction. The results of the research show that the network learning, network interaction, and network trust according to the function of the social network have a significant positive effect on the safety production behavior of the farmer households, of which the network learning has the greatest impact, the network interaction has the second, and the network trust is weak.
\end{abstract}

Keywords-Social network; Safety production behavior; Apple growers; Canonical correlation analysis

\section{INTRODUCTION}

"The country is based on the people; the people regard food as the heaven, and food and safety as the first." The quantity and quality of food are all related to human survival and physical health. With the continuous development of our country's economy and the gradual improvement of people's living standards, the issue of quality and safety of agricultural products has increasingly become the focus of attention. From production to consumption, agricultural products need to undergo many links. The production link is the key to the quality and safety of agricultural products. Therefore, whether farm households adopt safe production behavior is the most important human factor that affects the quality and safety of agricultural products ${ }^{[1]}$, and it is also an important content of agricultural product quality and safety at source management.

As an important part of social capital, social networks are widely used in economic research. China is a typical relational society, and forms a "differential order pattern" in which behavioral orientation is based on the principle of closeness and difference. ${ }^{[2]}$ Especially in rural areas, establishing a social network based on blood and geopolitics is an important mechanism for information sharing and resource allocation ${ }^{[3]}$. As a key social capital ${ }^{[3]}$, social networks are not only a relationship between specific individuals, but also can be used as an informal institutional arrangement ${ }^{[4-6]}$, existing at the collective, organizational and institutional level, and formal The systems complement each other and jointly strengthen the role of system norms, which should have an important impact on the farmers' safe production behavior. So, can social

Fund Project: Humanities and Social Sciences Project of the Ministry of Education: Research on the Safe Production Behavior of Apple Farmers under the Background of "Internet +": Transaction Costs, Farmers' Cognition and Behavior Decisions (16XJA790006) networks improve farmers' safe production behavior? What is the mechanism by which social networks affect farmer households' safety production behavior? The answers to the above questions have important theoretical and practical significance for the government to promote the development of the apple industry, solve the quality and safety issues of agricultural products, and improve people's quality of life and health.

Based on the above background, this paper makes use of the micro-survey data of 186 farmer households in the main apple producing areas of Liquan County, Xianyang City, Shaanxi Province, and divides the social network into three dimensions: network learning, network trust, and network interaction according to their functions. Each dimension is calculated. Comprehensive score, construct social network factor group. Using typical correlation analysis, the article conducts empirical research on the relationship between social networks and farmers' safe production behavior.

\section{VARIABLE MEASUREMENT}

\section{A. Variable description and main variable measurement}

Social network is a latent variable. Its measurement problem has been controversial for a long time. In terms of specific operations, scholars mainly use a number of social network indicators to obtain social network indicators through exploratory factor analysis (EFA). The larger the index value, the higher the household social network stock. This paper applies the micro survey data of 186 farmer households in the main apple producing area of Liquan County, Xianyang City, Shaanxi Province, and makes a factor analysis on the social network variables. The KMO test value of the sample is 0.812 , and the approximate Chi-square of Bartlett's spherical test is 16402.021 ( $\operatorname{sig}=0.000)$, indicating that the sample data is suitable for factor analysis. The software used is SPSS 22.0.”.

TABLE I. VARIABLE CALCULATION

\begin{tabular}{|c|c|}
\hline Index & Definition \\
\hline Online Learning C & \\
\hline $\begin{array}{c}\text { Do you often exchange } \\
\text { pesticides with neighboring } \\
\text { farmers? C1 }\end{array}$ & $\begin{array}{c}1 \text { to } 5 \text { represent never, } \\
\text { occasionally, usually, often, } \\
\text { frequently }\end{array}$ \\
\hline
\end{tabular}




\begin{tabular}{|c|c|}
\hline \multicolumn{2}{|c|}{ Cont. to TABLE I } \\
\hline $\begin{array}{l}\text { Do you often visit other } \\
\text { farmers' demonstration farms } \\
\text { and learn from their pesticide } \\
\text { application practices?C2 }\end{array}$ & $\begin{array}{l}1 \text { to } 5 \text { represent never, } \\
\text { occasionally, usually, often, } \\
\text { frequently }\end{array}$ \\
\hline $\begin{array}{l}\text { Do you often work with } \\
\text { others to solve pesticide } \\
\text { application problems? C3 }\end{array}$ & $\begin{array}{c}1 \text { to } 5 \text { represent never, } \\
\text { occasionally, usually, often, } \\
\text { frequently }\end{array}$ \\
\hline \multicolumn{2}{|l|}{ Network Interaction D } \\
\hline $\begin{array}{c}\text { Do you often communicate } \\
\text { with pesticide distributors? } \\
\text { D3 }\end{array}$ & $\begin{array}{c}1 \text { to } 5 \text { represent never, } \\
\text { occasionally, usually, often, } \\
\text { frequently }\end{array}$ \\
\hline $\begin{array}{l}\text { Do you often communicate } \\
\text { with consumers? D4 }\end{array}$ & $\begin{array}{l}1 \text { to } 5 \text { represent never, } \\
\text { occasionally, usually, often, } \\
\text { frequently }\end{array}$ \\
\hline $\begin{array}{l}\text { Do you often communicate } \\
\text { with Apple purchasers? D5 }\end{array}$ & $\begin{array}{l}1 \text { to } 5 \text { represent never, } \\
\text { occasionally, usually, often, } \\
\text { frequently }\end{array}$ \\
\hline \multicolumn{2}{|l|}{ Network trust E } \\
\hline $\begin{array}{c}\text { Do you think pesticide } \\
\text { spraying has a great impact } \\
\text { on food safety? E2 }\end{array}$ & $\begin{array}{c}1 \text { to } 5 \text { represent never, } \\
\text { occasionally, usually, often, } \\
\text { frequently }\end{array}$ \\
\hline $\begin{array}{l}\text { How do you think consumers } \\
\text { attach importance to apple } \\
\text { pesticide residue? E3 }\end{array}$ & $\begin{array}{l}1 \text { to } 5 \text { represent never, } \\
\text { occasionally, usually, often, } \\
\text { frequently }\end{array}$ \\
\hline $\begin{array}{l}\text { According to your } \\
\text { understanding, do you think } \\
\text { that the problem of pesticide } \\
\text { residues in apples has a great } \\
\text { impact on consumers' health? } \\
\text { E4 }\end{array}$ & $\begin{array}{l}1 \text { to } 5 \text { represent never, } \\
\text { occasionally, usually, often, } \\
\text { frequently }\end{array}$ \\
\hline \multicolumn{2}{|l|}{$\begin{array}{l}\text { Safe Production Behavior } \\
\text { F }\end{array}$} \\
\hline $\begin{array}{c}\text { What is the concentration of } \\
\text { pesticide you use?F1 }\end{array}$ & $\begin{array}{l}1 \text { to } 5 \text { represent fairly low, } \\
\text { low, medium, and high, } \\
\text { respectively, quite high }\end{array}$ \\
\hline $\begin{array}{l}\text { The time interval between } \\
\text { your last spraying of } \\
\text { pesticides to picking F3 }\end{array}$ & $\begin{array}{c}{[5,15]=1 ;[16,25]=2 ;[26,35]=3 ;} \\
{[36,45]=4 ;[46,+\infty]=5}\end{array}$ \\
\hline
\end{tabular}

In order to further give more reasonable economic meaning to the common factors, the maximum variance method was used to rotate the factors. Three common factors with characteristic roots greater than 1 were obtained, and the cumulative variance contribution rate was $63.170 \%$. The common factor 1 variance contribution rate is $28.915 \%$. The more exchanges of pesticide application experience with neighboring farmers, the more visits to the demonstration farms of other farmers, and the more frequent the application of pesticides, and the more frequent the joint use of pesticides to solve pesticide application problems, the better the farmers' learning results and the greater their progress. The common factor 1 reflects the learning function of rural households in the social network, so it is named as online learning (C).

The common factor 2 has a variance contribution rate of $18.732 \%$. Exchanges with pesticide dealers, consumer exchanges, and exchanges with Apple buyers are all conducive to the flow of information and access, so it is named network interaction (D).

The common factor 3 variance contribution rate reached $15.523 \%$. The impact of pesticide spraying on food safety, the importance of consumers' concerns regarding pesticide residues in apples, and the impact of apple pesticide residues on consumers' health are considered to measure the moral hazard of farmers to consumers. Therefore, they are named as networks. Trust (E).

In order to simplify the analysis of the problem, according to the results of the factor analysis, the comprehensive scores of the network learning (C), the network interaction (D), and the network trust (E) in the social network are obtained.

\section{CANONICAL CORRELATION ANALYSIS AND MAIN CONCLUSIONS}

\section{A. The basic idea of the canonical correlation analysis}

The process of canonical correlation analysis is as follows:

Assume that there are two sets of random variables $X=\left(x_{1}, \cdots, x_{p}\right)^{T}, Y=\left(y_{1}, \cdots, y_{q}\right)^{T}$, and $\mathrm{Z}$, which are $\mathrm{n}$ times normalized observations of the $\mathrm{p}+\mathrm{q}$ dimensional population:

$$
Z=\left(\begin{array}{cccccc}
x_{11} & \cdots & x_{1 p} y_{11} & \cdots & y_{1 q} \\
x_{21} & \cdots & x_{2 p} y_{21} & \cdots & y_{2 q} \\
\cdots & \cdots & \cdots & \cdots & \cdots & \cdots \\
x_{n 1} & \cdots & x_{n p} y_{n 1} & \cdots & y_{n q}
\end{array}\right)
$$

First, the correlation coefficient matrix $R$ is calculated, and $R$ is divided into $R=\left(\begin{array}{ll}R_{11} & R_{12} \\ R_{21} & R_{22}\end{array}\right)$, where $R_{11}$ and $R_{22}$ are the correlation coefficient arrays of the first group and the second group respectively, and $R_{12}=R_{21}{ }^{T}$ is the correlation coefficient matrix of the first group and the second group of variables.

Then find the typical correlation coefficient and typical variables. First, find the eigenvalue $M_{1}=R_{11}{ }^{-1} R_{12} R_{22}^{-1} R_{21}$ of $\lambda_{i}^{2}$, the eigenvector $a_{i} ;$ the eigenvalue $M_{2}=R_{22}{ }^{-1} R_{21} R_{11}^{-1} R_{12}$ of $\lambda_{j}^{2}$, the eigenvector $b_{j}$, then the typical variables are:

$$
\begin{gathered}
u_{1}=a_{1}^{T} X, v_{1}=b_{1}^{T} Y ; u_{2}=a_{2}^{T} X, v_{2}=b_{2}^{T} Y ; \ldots \\
u_{t}=a_{t}^{T} X, v_{t}=b_{t}^{T} Y(t \leq \min (p, q))
\end{gathered}
$$

Note

$$
U=\left(u_{1}, u_{2}, \cdots, u_{t}\right)^{T}, V=\left(v_{1}, v_{2}, \cdots, v_{t}\right)^{T}
$$

Finally, the significance test of the typical correlation coefficient $\lambda_{i}$ is performed, and the typical structure analysis is performed. 
The two sets of variables set in this paper are the social network factor group and the farmer household safety production behavior group. The social network factor group includes: network learning (C), network interaction (D), and network trust $(\mathrm{E})$; the household safety production behavior group includes: The number of pesticides used during one growth cycle $\left(F_{1}\right)$, the time between the last spraying of pesticides and picking $\left(F_{3}\right)$.

\section{B. Typical correlation analysis}

1) Canonical Correlation Coefficient and Its Test

The social network factor group and the farmer household safety production behavior group are calculated and the typical correlation coefficient is shown in Table 3:

TABLE II. TYPICAL CORRELATION COEFFICIENTS

\begin{tabular}{lll}
\hline & 1 & 2 \\
\hline $\begin{array}{l}\text { Typical correlation } \\
\text { coefficient }\end{array}$ & 0.693 & 0.231 \\
\hline
\end{tabular}

It can be seen from Table 2 that the first column is the first typical correlation coefficient, which is 0.693 , indicating that the first group of typical variables are closely related. The second set of typical correlation coefficients is too small, 0.231. So only consider the first typical correlation. However, to determine the significance of the correlation of typical variables, a statistical test of the correlation coefficient is still required.

The result is shown in the figure:

\begin{tabular}{|c|c|c|c|c|c|}
\hline & Statistic & df1 & dE2 & $\bar{F}$ & Prob>F \\
\hline Wilks' lambda & .930512 & 6 & 362 & 2.2122 & 0.0414 \\
\hline Pillai's trace & .0705455 & 6 & 364 & 2.2181 & 0.0408 \\
\hline Lawley-Hotelling trace & .0735417 & 6 & 360 & 2.2063 & 0.0419 \\
\hline Roy's largest root & .0514723 & 3 & 182 & 3.1227 & 0.0272 \\
\hline \multicolumn{6}{|c|}{ Test of significance of canonical correlations $1-2$} \\
\hline & Statistic & df1 & df 2 & $\bar{F}$ & Prob>F \\
\hline Wilks' lambda & .930512 & 6 & 362 & 2.2122 & 0.0414 \\
\hline \multicolumn{6}{|c|}{ Test of significance of canonical correlation 2} \\
\hline & Statistic & df1 & df2 2 & $\mathbf{F}$ & Prob>F \\
\hline Wilkg' lambda & .978407 & 2 & 182 & 2.0083 & 0.1372 \\
\hline
\end{tabular}

Fig. 1. Typical correlation coefficient significance test

From the above figure, we can see that the first canonical correlation coefficient passed the significance test at the significance level of 0.05 , that is, the correlation between the first canonical correlation variables is significant, and the social network factor group can be used to explain the safety production behavior of the farmers.

\section{2) Canonical Correlation Model}

This article uses standardized typical coefficients to give a typical correlation model:

$$
\begin{aligned}
& U_{1}=0.8763 C+0.5775 D+0.2236 E \\
& V_{1}=0.4533 F_{1}+0.8167 F_{3}
\end{aligned}
$$

According to the first set of typical correlation equations, the main influencing factors in the social network factor group are $\mathrm{C}$ and D (typical coefficients are 0.8763 and 0.5775 , respectively). This shows that the main factor affecting the safety production behavior of rural households in the social network factor group is network learning ( C) interaction with the network (D); the first typical variable $V_{1}$ in farmer's safety production behavior is highly positively correlated with $F_{1}$ and $F_{3}$, and the one most affected by social network factors is the time interval from the last spraying of pesticide to picking $\left(F_{3}\right)$, followed by a The number of pesticides used in the growth cycle $\left(F_{1}\right)$.

\section{3) Typical structure}

The structural analysis is based on the correlation coefficient between the original variable and the typical variable, as shown in Table 3:

TABLE III. STRUCTURE ANALYSIS

\begin{tabular}{|l|l|l|}
\hline & $U_{1}$ & $V_{1}$ \\
\hline $\mathrm{C}$ & 0.8273 & 0.3831 \\
\hline $\mathrm{D}$ & 0.5312 & 0.2312 \\
\hline $\mathrm{E}$ & 0.2474 & 0.0547 \\
\hline & $U_{1}$ & $V_{1}$ \\
\hline$F_{1}$ & 0.2946 & 0.2652 \\
\hline$F_{3}$ & 0.9256 & 0.3601 \\
\hline
\end{tabular}

As shown in Table 3, C and D are highly correlated with the first typical variable $U_{1}$ of the social network factor group, which shows that online learning and network interaction play a dominant role in reflecting social networks, $V_{1}$ and $F_{3}$ that online learning is the top priority. The correlation coefficient between the first typical variable of farmer's safe production behavior and the higher one reflects that the time interval from the last spraying of pesticide to picking $\left(F_{3}\right)$ reflects the dominant position of safety behavior of farmer households. Due to the high correlation between the first pair of typical variables, the three main variables in the "Social Network Factor Group" are related to the first typical variable in the safe production behavior of farmers; and the $F_{3}$ of the safe production behavior of the farmers is also related to the first typical variable of the "influence factor group". The first typical variable is also relevant. This consistency reflects the essential influence of the "social network factor group" on the safe production behavior of rural households in terms of quantity, which is in good agreement with the actual economic linkages of the indicators. This shows that the results of canonical correlation analysis have a high degree of credibility.

\section{Analysis and Conclusion of the Relationship between Social Network and Farmers' Safe Production Behavior}

According to the results of canonical correlation analysis, the main factors affecting the safety production behavior of rural households in the social network factor group are network 
learning (C) and network interaction (D). Among them, online learning has the greatest impact because of the flow of information through online learning. It will have a certain diffusion effect on farmer's behavior of safe production and promote learning. As a result, certain behavior tends to be consistent in safety production behavior between network members, and it will gradually tend to safe production behavior At the same time, the spread of safety production technology through online learning is more conducive to farmers' safe production behavior. The impact of network interaction on farmer households' safety production shows that peasants can have a more comprehensive and scientific understanding of safety production behaviors by communicating with different types of subjects in social network members, and this understanding will play a key role when farmers choose and apply pesticides. Although network trust has the least impact on the safety production behavior of farmers in social network, it still has a certain influence. It shows that although the farmers themselves may have moral hazard behaviors, farmers and consumers have great differences in pesticide residues. However, through the establishment of a trust relationship, it still helps to promote the safe production behavior of farmers.

\section{CONCLUSION}

This paper takes 186 scattered rural households in Liquan County, Xianyang City, Shaanxi Province as samples. Based on the canonical correlation analysis, this paper studies the influence of social networks on farmers' safety production behavior. The results of the research show that the network learning, network interaction, and network trust according to the function of the social network have a significant positive effect on the safety production behavior of the farmer households, of which the network learning has the greatest impact, the network interaction has the second, and the network trust is weak. The research findings of this paper show that strengthening and expanding the social network of farmers will contribute to the safe production behavior of farmers. The implications are as follows:

1. Because farmers can acquire knowledge about pesticide selection and canonical application through online learning, the accumulation of knowledge will form individual human capital, which will have a certain guiding role for their own behavior. Therefore, the government should pay attention to the construction of farmers' social networks, actively build a platform for exchanges between farmers, and promote the dissemination of knowledge and technology of safe production among farmers. Farmers learn from each other and work together to produce safely.

2. Because the farmers communicate with the different types of subjects in the social network, they will have a more comprehensive and scientific understanding of the safety production behavior. Therefore, the government should actively promote exchanges between farmers and the outside world; for example, provide farmers with regular agricultural resources distribution. The platform for business exchanges allows farmers to have more opportunities to choose agricultural materials with appropriate prices and guaranteed quality, thus reducing the safe production costs of farmers to a certain extent and promoting the safe production of farmers.

3. Farmers and consumers have great differences in the perception of pesticide residues. Farmers have relatively low standards for safe production, and may have neglected the issue of pesticide residues. Consumers have higher standards for safe production. Pesticide residues are more sensitive. If farmers cannot directly reach consumers, they will not be able to obtain consumers' attitudes toward safe production. Therefore, village heads should organize more exchanges between farmers and consumers to stimulate their safe production behavior.

\section{REFERENCES}

[1] Hua Hongjuan. Research on the Impact of Agricultural Production and Operation Organization Mode on Farmers' Food Safety Production Behavior-Based on the Survey of Grape Production Areas in Jiangsu Province[D]. Nanjing Agricultural University, 2011, In Chinese.

[2] Fei Xiaotong. Native China: Revised [M]. Shanghai People's Publishing House, 2013, In Chinese.

[3] Liang Yi. Selected Works of Liang Yi [M]. Jilin People's Publishing House, 2005, In Chinese.

[4] Chen Gang, Li Shu. How can the government make people happy? - An empirical study on the influence of government quality on the wellbeing of residents[J].Management World.2012(08), In Chinese.

[5] Zhang Min, Tong Lijing, Xu Haoran. Social Network and Corporate Risk Assumption-Based on Empirical Evidence from Listed Companies in China[J].Management World.2015(11), In Chinese.

[6] Besley T, Case A. Does Electoral Accountability Affect Economic Policy Choices? Evidence from Gubernatorial Term Limits[J]. Nber Working Papers, 1993, 110(3):769-798, In Chinese.

[7] Glaeser E L, Kallal H D, Scheinkman J A, et al. Growth in Cities[J]. Journal of Political Economy, 1992, 100(6):1126-1152, In Chinese.

[8] Munshi K. Social learning in a heterogeneous population: technology diffusion in the Indian Green Revolution[J]. Journal of Development Economics, 2004, 73(1):185-213, In Chinese. 